This item was submitted to Loughborough's Research Repository by the author.

Items in Figshare are protected by copyright, with all rights reserved, unless otherwise indicated.

\title{
Multi-port energy router for DC grid clusters
}

PLEASE CITE THE PUBLISHED VERSION

https://doi.org/10.1109/icdcm50975.2021.9504679

PUBLISHER

IEEE

VERSION

AM (Accepted Manuscript)

\section{PUBLISHER STATEMENT}

(c) 2021 IEEE. Personal use of this material is permitted. Permission from IEEE must be obtained for all other uses, in any current or future media, including reprinting/republishing this material for advertising or promotional purposes, creating new collective works, for resale or redistribution to servers or lists, or reuse of any copyrighted component of this work in other works.

\section{LICENCE}

All Rights Reserved

\section{REPOSITORY RECORD}

Sun, Linfeng, Wei Jiang, Seiji Hashimoto, and Zhengyu Lin. 2021. "Multi-port Energy Router for DC Grid Clusters". Loughborough University. https://hdl.handle.net/2134/16438362.v1. 


\title{
Multi-port Energy Router for DC Grid Clusters
}

\author{
Linfeng Sun ${ }^{\dagger}$, Wei Jiang ${ }^{\dagger}$, Seiji Hashimoto ${ }^{\ddagger}$ and Zhengyu $\operatorname{Lin}^{\S}$ \\ ${ }^{\dagger}$ Department of Electrical Engineering, Yangzhou University, Yangzhou 225127, China \\ Email jiangwei@yzu.edu.cn \\ $\ddagger$ Division of Electronic and Informatics, Gunma University, Kiryu 376-8515, Japan \\ Email hashimotos@gunma-u.ac.jp \\ ${ }^{\S}$ Centre for Renewable Energy Systems Technology (CREST), Loughborough University, Loughborough LE11-3TU, UK \\ EmailZ.Lin@lboro.ac.uk
}

\begin{abstract}
DC micro-grid comes an increasingly popular solution for local energy integration and dispatch. Individual dc micro-grid can operate in both island and grid-tie mode. The past research mainly focused on the dc-ac grid-tie power management while dc-dc tie mode might dominate future smart power distribution networks. This paper proposed a multiport energy router to multiplex dc power from multiple dc communities whose bus voltage is operated at very close levels . The proposed energy router works a KCL "super node". It includes a partial power topology which can direct the dc current flow between any two buses or to the local energy storage by only taking the bus voltage differences. To fit the modulation and control into industrial standard framework, also considering the flexibility of controlling the energy storage current, multidimension space vector modulation and instantaneous power theory are employed to regulate the de power flow. Multiple operation scenarios are investigated to prove the feasibility of the energy router by simulation and experiment. The power transfer efficiency experiment of partial power topology based on standard half-bridges is verified.
\end{abstract}

Index Terms-dc micro-grid, energy router, multi-port converter, static three-dimensional space vector modulation technology, modified $p-q$ theory, partial-power conversion

\section{INTRODUCTION}

The similarity between the data flow and energy flow renders the new concept of energy internet. The data router divert data in a timely manner for different end-users, acting as the vital role to distribute information. From the energy domain, people have conceived excellent components, systems and methods to generate, transmit and distribute the energy in form of electric power. The power electronic technology enabled high efficient energy harvesting and utilization. DC microgrids has been proposed for almost 20 years, numerous research topics have been investigated on RES and ESS integration, stability control and planning etc. As the scales of the micro-grid continue to grow, issues such as intergrid power exchange demand emerges. The energy router, which is firstly proposed by the future renewable electric energy delivery and management (FREEDM) [1] [2] system center, can direct the flow of energy between storage devices, loads and power generation systems. People have investigated numerous possibilities of the topology and implementation of energy routers.

Among the options, SST-based energy router adopts singlestage or multi-stage topology [3]- [5] to realize the power flow of the buses of different voltage levels, and modular multilevel converter (MMC) topology [6] is also used in subsequent research. MPC-based energy router can realize energy regulation between distributed devices in a DC micro-grid [7], or among distributed micro-grids [8]. Scholars' research on MPC-based energy routers is mainly on circuit topology [7], [8]- [10].

In dc systems, power distribution between dc buses are not necessarily operating at the nominal value, and power flow can be controlled by controlling voltage difference and impedance between dc buses [11]- [14], [20] [21]. Previous research [15][19] adopts traditional cascade power conversion method to interconnect the MVDC network, which requires full power processing capability; past literature indicates that by topology and soft switching design, the cascaded conversion can achieve ultra high efficiency. Iowever, the power loss is still high due to the fact that grid-to-grid power transfer is usually at MW level. Therefore, there is no limit on the road to efficiency. In this paper, a partial power [22] [23] energy router (PPER) topology is proposed. The output port of the PPER only handle the voltage stress of voltage difference between two DC buses, which renders much lower "handling power" comparing to traditional methods.

\section{DC CLUSTER OPERATION AND ENERGY ROUTER TOPOLOGY}

\section{A. dc cluster energy exchange}

The PPER is used in a multi-dc-bus scenario where DC community $\mathrm{A}, \mathrm{B}$, and $\mathrm{C}$ can operate in either island mode or grid-tie mode, as shown in Fig. 1. To balance load and renewable energy generation, each individual DC community can import or export dc power to the PPER, which connect each dc bus as the "super node". The PPER can control the power flow between any two bus. If the entire system has surplus energy or demand more power, the energy storage that sits near the PPER can offer the power leverage.

\section{B. the partial power conversion}

The partial power conversion connect the source and the load in a serial fashion. As shown in fig 2, with the presence of two voltage buses, the partial power converter serves as the current link between two voltage buses. However, according to KVL, the current link either generates power or consumes power, which either comes from or go back into either of the 


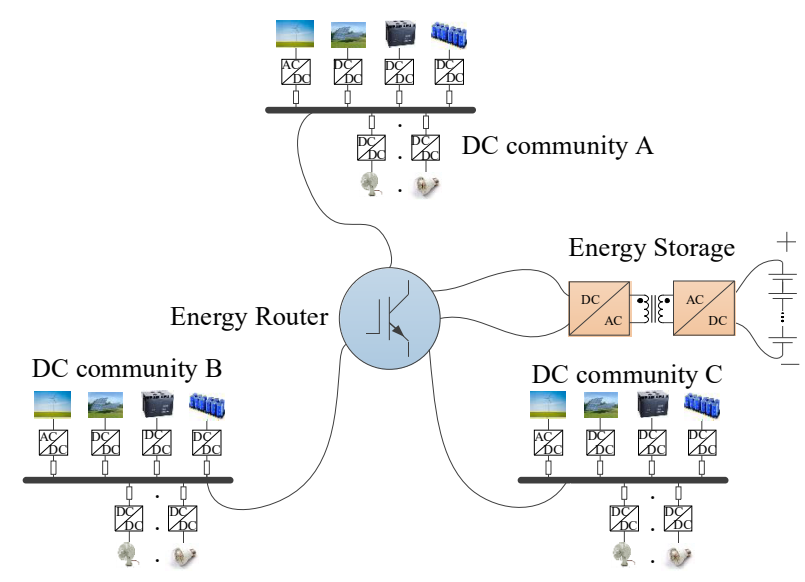

Fig. 1. Proposed energy router connecting multiple dc communities

DC buses. One can easily find that by using partial power technology, the absolute loss is much less than that of the cascaded conversion circuit. It means, by investing limited amount of operational power, the partial power circuit can easily help transfer much higher power between the sources and the loads.

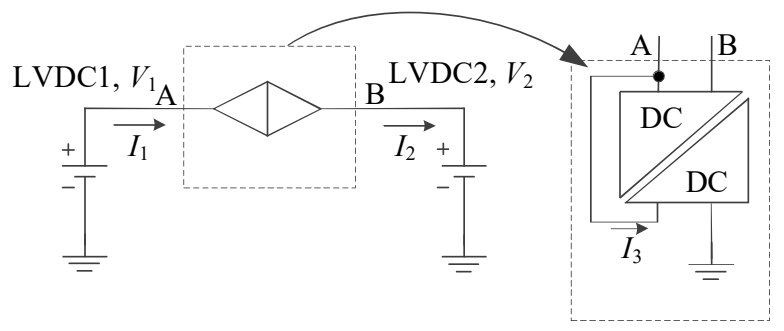

Fig. 2. Partial power converter that takes power from any bus

$$
\begin{aligned}
P_{1 l o s s} & =V_{1} I_{1}(1-\eta) \\
P_{2 l o s s} & =\left(V_{2}-V_{1}\right) I_{2} \frac{1-\eta}{\eta} \\
\frac{P_{1 l o s s}}{P_{2 l o s s}} & =\frac{V_{1} I_{1}(1-\eta)}{\left(V_{2}-V_{1}\right) I_{2} \frac{1-\eta}{\eta}}=\frac{V_{2} I_{2}}{\left(V_{2}-V_{1}\right) I_{2}}>1
\end{aligned}
$$

\section{PPER topology}

The grid interface part of the PPER is based standard halfbridge cells. The middle point of each standard half-bridge is connected to the local energy storage and he DC communities. The DC community energy flow can be realized by controlling the inductor current at the output port of each DC community. Following the KCL, it is easy to understand that only the power flow of $n-1$ DC communities can be fully controlled by the PPER. If one want to precisely control the power flow of all the DC communities on the ports, one extra port has to be created and connected to the energy buffer, the energy storages. The proposed topology shown in Fig. 3, where $V_{L V 1}$, $V_{L V 2}, V_{L V 3}$ indicate the dc community bus voltage, and the floating voltage $V_{M V}$ indicates the dc energy pool voltage which is generated by the energy storage and its isolated bidirectional dc-dc converter.

\section{Modelling of energy router topology and Modulation strat- egy}

The four half-bridges of the proposed PPER topology work in a complementary mode, which makes the circuit have 16 switching states. The average equivalent model of the topology can be obtained by using the switching function and the averaging operator successively, as indicated in Eq. (4).

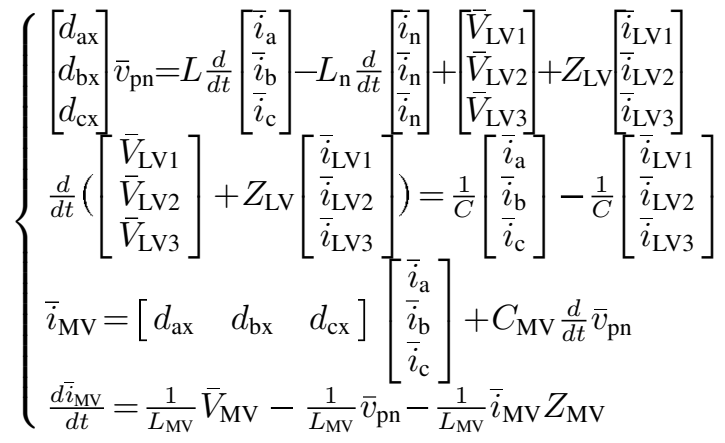

In the PPER circuit, there is a coupling relationship between the three-dc-community ports and the energy storage port. In order to solve the undesirable dynamic interaction, it is proposed to study the control of the standard multi-bridge arm topology under the static space vector coordinate. Clarke coordinate transformation is applied to Eq. (4) to obtain the average equivalent model in $\alpha \beta \gamma$ coordinate system, as indicated in Eq. (5).

$$
\left\{\begin{array}{l}
{\left[\begin{array}{ccc}
L & 0 & 0 \\
0 & L & 0 \\
0 & 0 & L+3 L_{\mathrm{n}}
\end{array}\right] \frac{d}{d t}\left[\begin{array}{c}
\bar{i}_{\alpha} \\
\bar{i}_{\beta} \\
\bar{i}_{\gamma}
\end{array}\right]=\left[\begin{array}{c}
d_{\alpha} \\
d_{\beta} \\
d_{\gamma}
\end{array}\right] \bar{v}_{\mathrm{pn}}\left[\begin{array}{c}
\bar{v}_{\alpha} \\
\bar{v}_{\beta} \\
\bar{v}_{\gamma}
\end{array}\right]} \\
\frac{d}{d t}\left[\begin{array}{l}
\bar{v}_{\alpha} \\
\bar{v}_{\beta} \\
\bar{v}_{\gamma}
\end{array}\right]=\frac{d}{d t}\left(\left[\begin{array}{l}
\bar{V}_{\alpha 1} \\
\bar{V}_{\beta 1} \\
\bar{V}_{\gamma 1}
\end{array}\right]+Z_{\mathrm{LV}}\left[\begin{array}{l}
\bar{i}_{\alpha 1} \\
\bar{i}_{\beta 1} \\
\bar{i}_{\gamma 1}
\end{array}\right]\right)=\frac{1}{C}\left[\begin{array}{c}
\bar{i}_{\alpha} \\
\bar{i}_{\beta} \\
\bar{i}_{\gamma}
\end{array}\right]-\frac{1}{C}\left[\begin{array}{c}
\bar{i}_{\alpha 1} \\
\bar{i}_{\beta 1} \\
\bar{i}_{\gamma 1}
\end{array}\right] \\
\frac{d}{d t} \bar{v}_{\mathrm{pn}}=\frac{\bar{i}_{\mathrm{MV}}}{C_{\mathrm{MV}}}-\frac{1}{C_{\mathrm{MV}}}\left[\begin{array}{lll}
d_{\alpha} & d_{\beta} & d_{\gamma}
\end{array}\right]\left[\begin{array}{c}
\bar{i}_{\alpha} \\
\bar{i}_{\beta} \\
\bar{i}_{\gamma}
\end{array}\right] \\
\frac{d \bar{d}_{\mathrm{MV}}}{d t}=\frac{1}{L_{\mathrm{MV}}} \bar{V}_{\mathrm{MV}}-\frac{1}{L_{\mathrm{MV}}} \bar{v}_{\mathrm{pn}}-\frac{1}{L_{\mathrm{MV}}} \bar{i}_{\mathrm{MV}} Z_{\mathrm{MV}}
\end{array}\right.
$$

The small disturbance is added to the average equivalent model in Eq. (5) at the steady-state operating point, and the transfer function of current to duty cycle can be obtained by separating the steady-state operating point, as indicated in Eq. (6).

$$
\frac{\tilde{i}_{k}}{\tilde{d}_{k}}=\frac{V_{\mathrm{pn}}\left(s C+\frac{1}{Z_{\mathrm{LV}}}\right)}{s^{2} \frac{L_{k}}{C}+s \frac{L_{k}}{Z_{\mathrm{LV}}}+1}
$$

where, the value of $k$ is $\alpha, \beta, \gamma$. When $k$ is $\alpha$ or $\beta$, the inductance $L_{k}$ in the transfer function is the single-port inductance $L$. When $k$ is $\gamma$, the inductance $L_{k}$ is the sum of the three-port inductance and the neutral inductance.

Clarke coordinate transformation is used on the DC community port voltages in 16 switching states, 16 static voltage vectors can be obtained as shown in Fig. 4. Therefore, the 


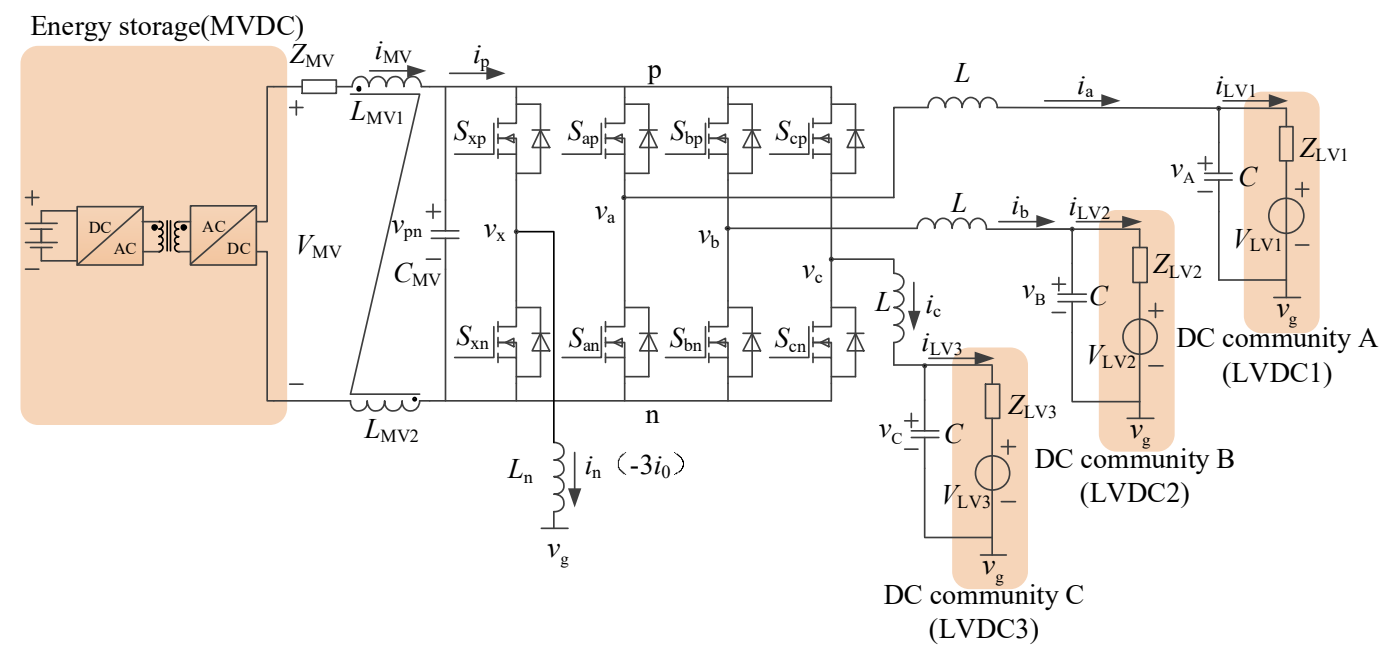

Fig. 3. Circuit topology for proposed PPER

traditional three-dimensional space vector modulation technology which is called 3D-SVM can be used to modulate the control variables $d_{\alpha}, d_{\beta}$ and $d_{\gamma}$ in the $\alpha \beta \gamma$ coordinate system to the control variables $d_{a}, d_{b}, d_{c}$ and $d_{x}$ in the $a b c$ coordinate system.

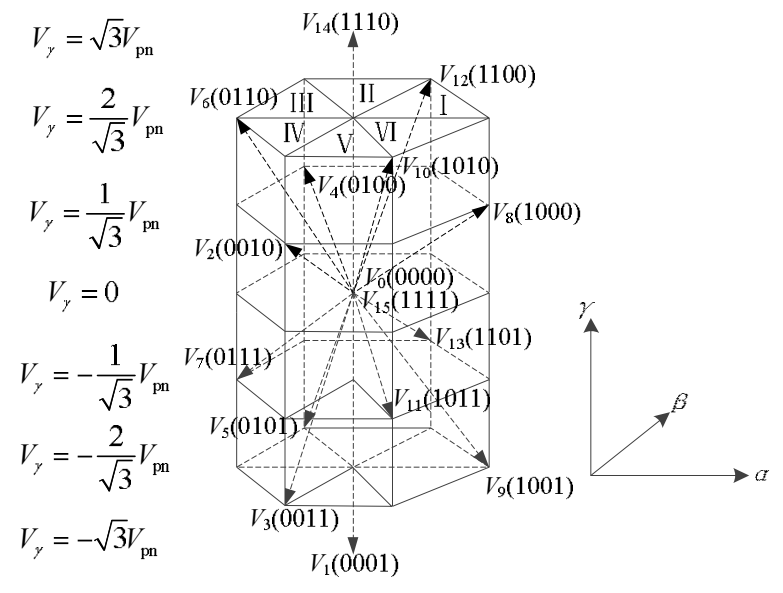

Fig. 4. three-dimensional space voltage vector of dc community port voltages in $\alpha \beta \gamma$ coordinate system

\section{CONTROL DESIGN AND VALIDATION}

\section{A. Current loop control design and simulation validation}

The power flow control of the PPER is based on the current loop control method. The control block diagram based on Eq. (6) is shown in Fig. 5. $G_{C k}(s)$ is the transfer function of the controller, and $G_{P W M}(s)$ is the control variable gain which is related to the energy storage voltage.

In order to realize the mutual verification of design, simulation and hardware systems, a scaled power version of PPER are selected for feasibility verification. Among them, the voltage of all DC communities is $12 \mathrm{VDC}$, and the floating voltage that comes from the energy storage is 36VDC. Some

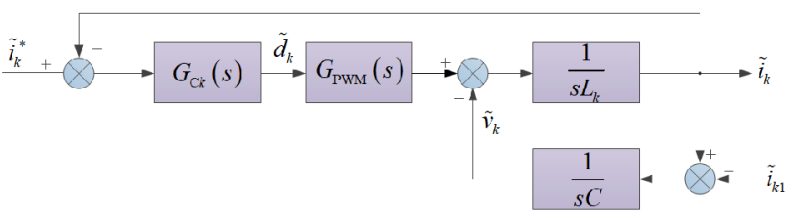

Fig. 5. Current control block diagram

modes in Table I are selected to verify that proposed PPER can realize the basic functions of DC community power regulation.

TABLE I

CURRENT REFERENCE VALUES OF $a b c$ AND $\alpha \beta \gamma$ COORDINATE SYSTEM

\begin{tabular}{|c|c|c|c|c|c|}
\hline$I_{L V 1}^{*}$ & $I_{L V 2}^{*}$ & $I_{L V 3}^{*}$ & $I_{\alpha}^{*}$ & $I_{\beta}^{*}$ & $I_{\gamma}^{*}$ \\
\hline 5 & 0 & 0 & 4.082 & 0 & 2.887 \\
\hline-5 & 0 & 0 & -4.082 & 0 & -2.887 \\
\hline 0 & 5 & 0 & -2.041 & 3.536 & 2.887 \\
\hline 0 & -5 & 0 & 2.041 & -3.536 & -2.887 \\
\hline 0 & 0 & 5 & -2.041 & -3.536 & 2.887 \\
\hline 0 & 0 & -5 & 2.041 & 3.536 & -2.887 \\
\hline
\end{tabular}

The simulation result shows that the proposed PPER topology can realize the basic bidirectional energy flow function of each DC community port under the control of current loop in Fig. 6. At $0.02 \mathrm{~s}$, a mode swap command is issued, the PPER still precisely track the designated reference commands. The simulation result also shows that the PPER has a more flexible mode fast switching capability during mode swap.

\section{B. Power flow control and simulation validation}

Compared with other three-phase instantaneous power theories, the modified $p-q$ theory is more suitable for the static $\alpha \beta \gamma$ coordinate system, and it is also applicable to the scenario where there are zero-sequence components in the three-phase four-wire system. The modified $p-q$ theory defines active power $p$ which includes zero-sequence power and the 


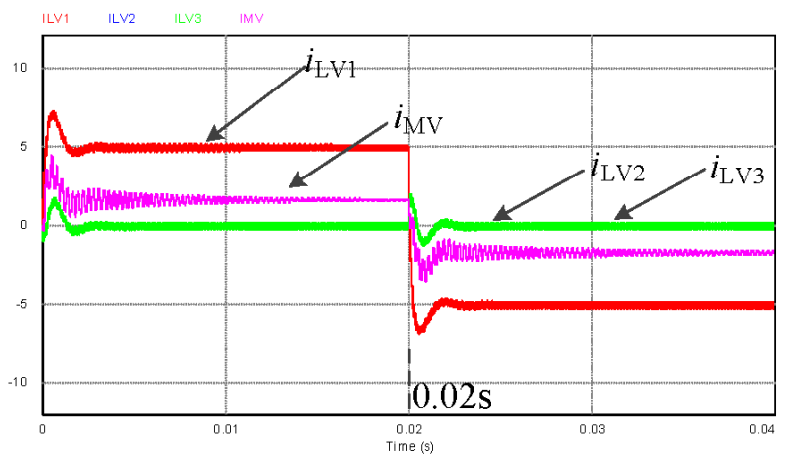

(a)

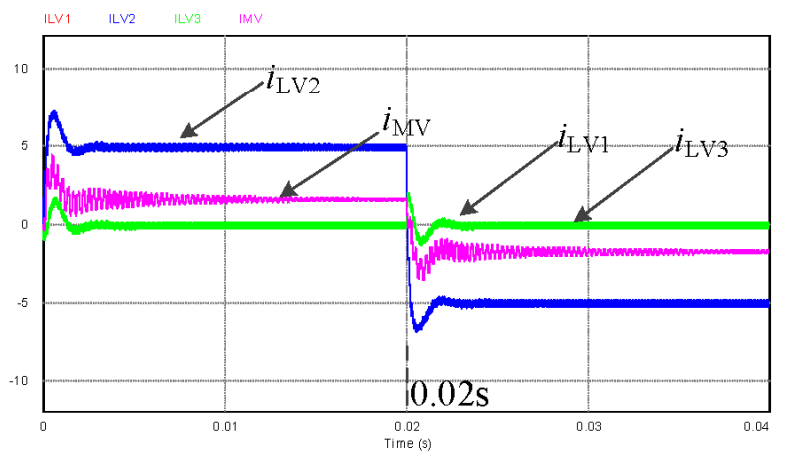

(b)

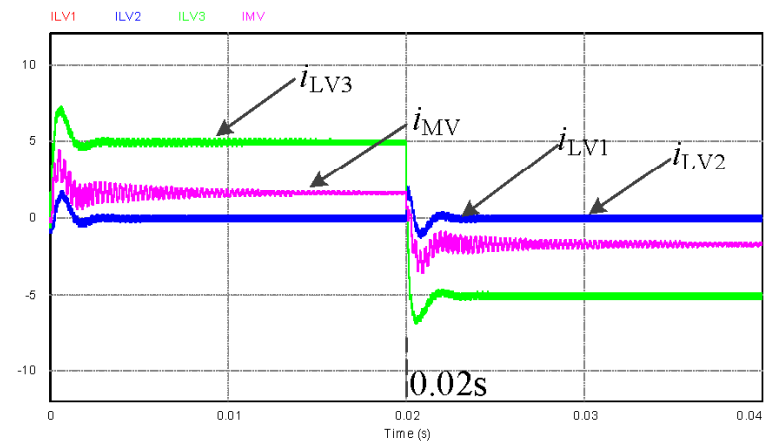

(c)

Fig. 6. Directed current flow among DC communities (a), (b), (c)

imaginary power vector composed of three elements, $q_{\alpha}, q_{\beta}$, and $q_{\gamma}$, as shown in Eq. (7).

$$
\left[\begin{array}{c}
p \\
q_{\alpha} \\
q_{\beta} \\
q_{\gamma}
\end{array}\right]=\left[\begin{array}{ccc}
v_{\alpha} & v_{\beta} & v_{\gamma} \\
0 & -v_{\gamma} & v_{\beta} \\
v_{\gamma} & 0 & -v_{\alpha} \\
-v_{\beta} & v_{\alpha} & 0
\end{array}\right]\left[\begin{array}{c}
i_{\alpha} \\
i_{\beta} \\
i_{\gamma}
\end{array}\right]
$$

In this research, the modified $p-q$ theory is applied to the DC system, and the mapping relationship of $p, q_{\alpha}, q_{\beta}$ and $q_{\gamma}$ in AC system and DC system is shown in Table II.

The power flow control method based on the modified $p-q$ theory is shown in Fig. 7. In the DC Grid Clusters, there is no need to perform real-time power compensation control on high-frequency mutation, and low-pass filters are used to filter out the high-frequency components of voltage and current. The control variables obtained by the current-mode control
TABLE II

INTERPRETATION OF INSTANTANEOUS POWER VARIABLES IN AC AND DC SYSTEMS

\begin{tabular}{|c|c|c|}
\hline $\begin{array}{c}\text { Instantaneous } \\
\text { power } \\
\text { variables }\end{array}$ & AC system & DC system \\
\hline$p$ & $\begin{array}{c}\text { instantaneous power } \\
\text { of the AC system }\end{array}$ & $\begin{array}{c}\text { transmission power } \\
\text { of energy storage }\end{array}$ \\
\hline$q_{\alpha}, q_{\beta}, q_{\gamma}$ & $\begin{array}{c}\text { power exchanged between } \\
\text { the phases without } \\
\text { delivering to load }\end{array}$ & $\begin{array}{c}\text { partial power exchanged } \\
\text { between the } \\
\text { three DC communities }\end{array}$ \\
\hline
\end{tabular}

is in $\alpha \beta \gamma$ coordinate system, but the actual control variables are the duty cycle of each half-bridge. Therefore, the control variable of each half-bridge can be calculated through 3DSVM modulation.

The simulation result shows that partial power transmission between multiple DC communities can be achieved by controlling the exchange power vector $q$ in Fig. 8. The energy storage does not transfer power, and the power $p$ is 0 . There is power exchange between the three DC communities, and the modulus of the exchange power vector $q$ of the $\alpha \beta \gamma$ coordinate system is not zero.

The simulation result shows that Power transmission between DC communities and storage can be achieved by controlling the energy storage $p$ in Fig. 9. Therefore, controlling the power $p$ and power vector $q$ can realize the flexible and arbitrary power transfer between the three DC communities and the energy storage.

\section{EXPERIMENTAL VALIDATION}

The PPER prototype is built, and the test bed in shown in Fig. 11. The ultra capacitor banks are used to simulate three DC community buses and the energy storage near the PPER.

\section{A. Partial power transfer efficiency experiment}

In order to verify the efficiency of partial power transfer, efficiency experiment is carried out using the converter in Fig. 2. When two DC communities are interconnected, the PPER topology is equivalent to a full bridge topology which is four-quadrant DC-DC topology. The input stage of PPER adopts a bi-directional dual active bridge DC-DC converter to provide floating DC energy buffer, and the output stage adopts current closed-loop control to realize a controllable current source. Connecting any DC community of the output stage of the converter to the input stage can obtain an efficient two-port partial power converter in Fig. 2.

The experimental waveforms of two DC communities with different voltage levels are shown in Fig. 10, and the power transfer level is about 200 watt. The power transfer efficiency are $96 \%$ and $95 \%$, respectively. Therefore, the partial power transfer method can improve the power transfer efficiency.

\section{B. validation of power routing}

Selected modes are tested to verify PPER's capability of power transfer and mode switch. Fig. 12 shows power transfer between multiple dc communities based on complex working 


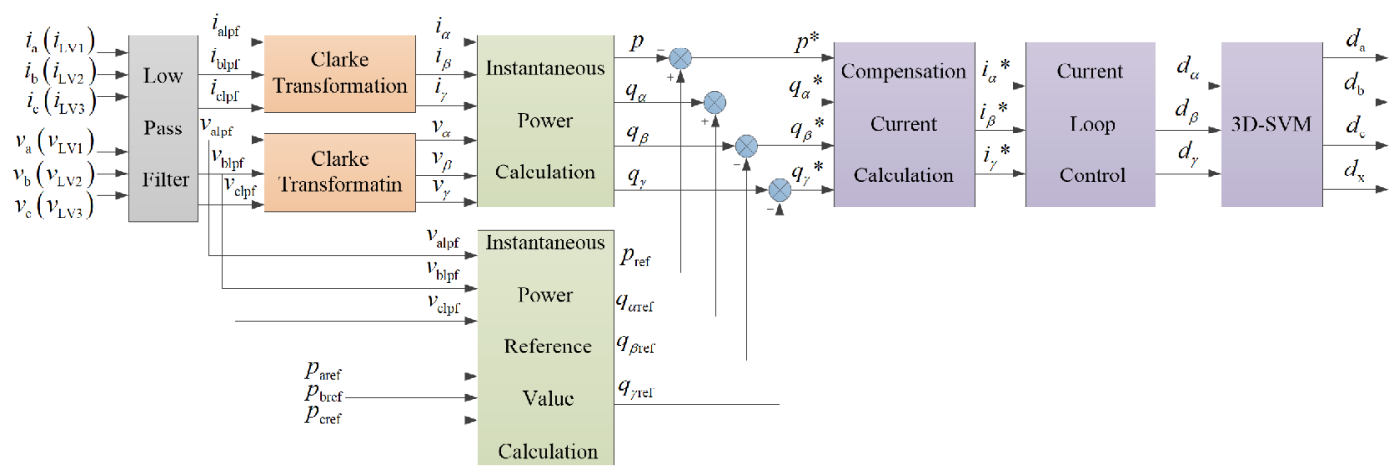

Fig. 7. Power flow control block diagram for three de communities

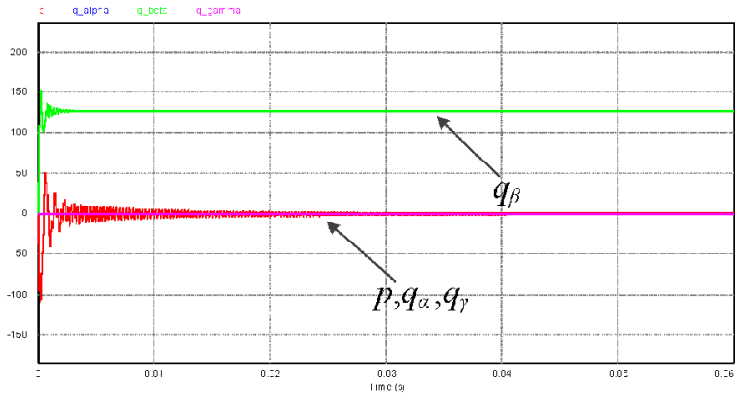

Fig. 8. Partial power transmission between DC communities by controlling power $q_{\alpha}, q_{\beta}, q_{\gamma}$

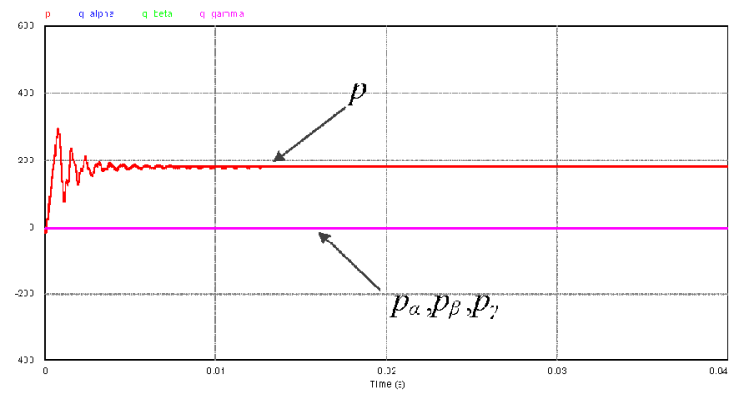

Fig. 9. Power transmission between DC communities and storage by controlling power $p$

conditions. Fig. 13 verify a real-world scenario, where the dc power is transferred among dc buses as well as the energy storage near the PPER; the mode swap is event based, and the PPER is able to respond to demand in time.

\section{CONCLUSION}

This paper proposes a PPER for dc microgrid cluster. The PPER can realize local centralized power distribution between dc communities and local energy storage. The proposed PPER adopts instantaneous power control theory and multidimensional space vector modulation, which offers instantaneous power transfer between dc buses and community energy storage. Partial power transfer of the proposed PPER has higher power transfer efficiency.

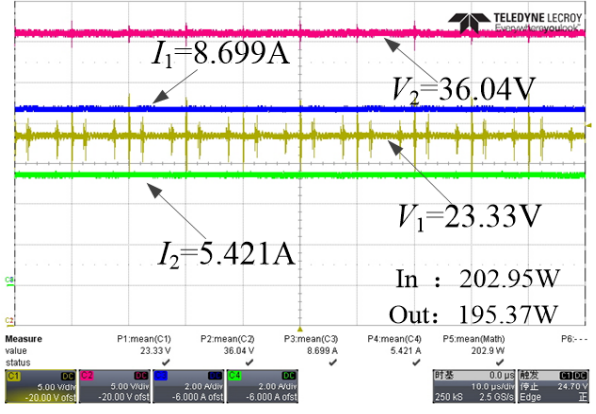

(a)

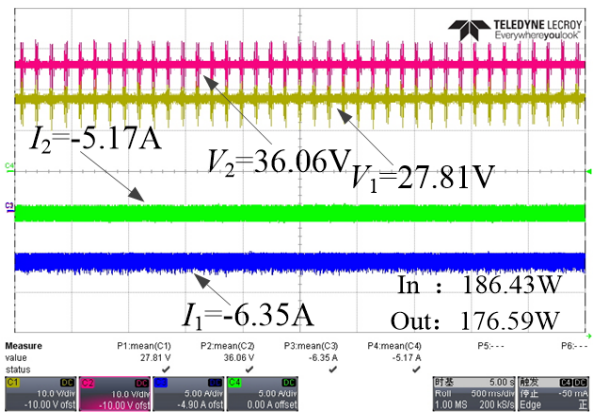

(b)

Fig. 10. Two quadrant operation efficiency test (a) $V_{1}>V_{2}$, (b) $V_{1}>V_{2}$

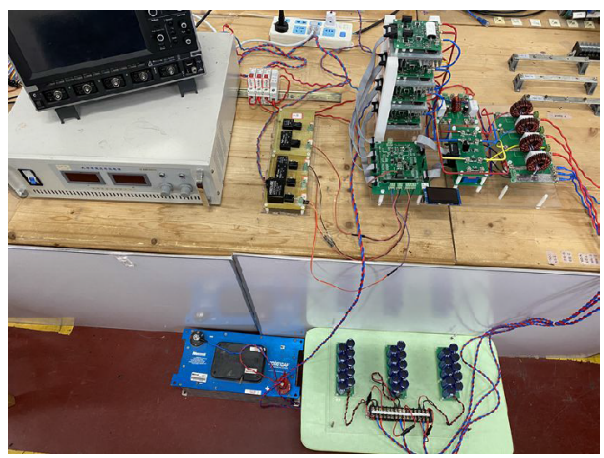

Fig. 11. PPER testplatform 


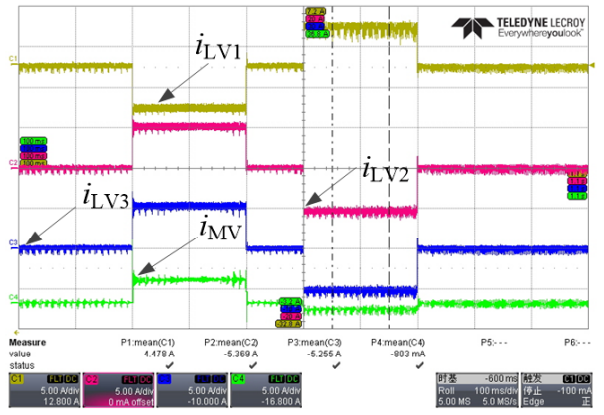

Fig. 12. Power transfer between multiple dc communities based on complex working condition

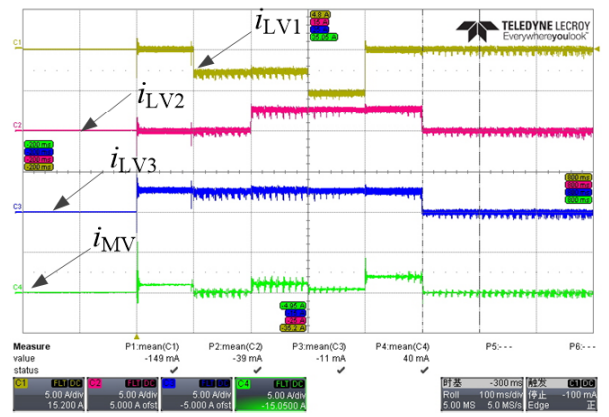

Fig. 13. Event-based power transfer between dc communities and storage

\section{ACKNOWLEDGEMENT}

This work is sponsored by Yangzhou City and Yangzhou University Joint Fund (YZ2020169) and YZU Teaching Lab Innovation Fund (zzyq202013)

\section{REFERENCES}

[1] A. Huang, "FREEDM system-a vision for the future grid, "IEEE PES General Meeting, pp. 1-4, 2010.

[2] A. Q. Huang, M. L. Crow, G. T. Heydt, J. P. Zheng and S. J. Dale, "The Future Renewable Electric Energy Delivery and Management (FREEDM) System: The Energy Internet," Proceedings of the IEEE, vol. 99, no. 1, pp. 133-148, Jan. 2011.

[3] B. Zhao, Q. Song, J. Li and W. Liu, "A Modular Multilevel DC-Link Front-to-Front DC Solid-State Transformer Based on High-Frequency Dual Active Phase Shift for HVDC Grid Integration," IEEE Transactions on Industrial Electronics, vol. 64, no. 11, pp. 8919-8927, Nov. 2017.

[4] H. Chen and D. Divan, "Design of a $10-\mathrm{kV}_{i} \in A$ Soft-Switching SolidState Transformer (S4T)," IEEE Transactions on Power Electronics, vol. 33, no. 7, pp. 5724-5738, July 2018.

[5] S. Madhusoodhanan et.al, "Solid-State Transformer and MV Grid Tie Applications Enabled by $15 \mathrm{kV} \mathrm{SiC}$ IGBTs and $10 \mathrm{kV}$ SiC MOSFETs Based Multilevel Converters," IEEE Transactions on Industry Applications, vol. 51, no. 4, pp. 3343-3360, July-Aug. 2015.

[6] M. Alharbi and S. Bhattacharya, "Scale-Up Methodology of a Modular Multilevel Converter for HVdc Applications," IEEE Transactions on Industry Applications, vol. 55, no. 5, pp. 4974-4983, Sept.-Oct. 2019.

[7] B. L. Nguyen, H. Cha, T. Nguyen and H. Kim, "Family of Integrated Multi-Input Multi-Output DC-DC Power Converters," 2018 International Power Electronics Conference (IPEC-Niigata 2018-ECCE Asia), pp. 3134-3139, 2018

[8] H. Wu, J. Zhang and Y. Xing, "A Family of Multiport Buck§̌CBoost Converters Based on DC-Link-Inductors (DLIs)," IEEE Transactions on Power Electronics, vol. 30, no. 2, pp. 735-746, Feb. 2015.

[9] W. Chen et.al, "A Novel Interline DC Power-Flow Controller (IDCPFC) for Meshed HVDC Grids," IEEE Transactions on Power Delivery, vol. 31, no. 4, pp. 1719-1727, Aug. 2016.
[10] H. Wu, P. Xu, H. Hu, Z. Zhou and Y. Xing, "Multiport Converters Based on Integration of Full-Bridge and Bidirectional DC-DC Topologies for Renewable Generation Systems," IEEE Transactions on Industrial Electronics, vol. 61, no. 2, pp. 856-869, Feb. 2014.

[11] H. Akagi, E. H. Watanabe and M. Aredes, "Instantaneous Power Theory and Applications to Power Conditioning," Wiley-IEEE Press, 2017.

[12] D. Strickland et.al, "A review of community electrical energy systems," 2016 IEEE International Conference on Renewable Energy Research and Applications (ICRERA), pp. 49-54, 2016.

[13] D. Kumar, F. Zare and A. Ghosh, "DC Microgrid Technology: System Architectures, AC Grid Interfaces, Grounding Schemes, Power Quality, Communication Networks, Applications, and Standardizations Aspects," IEEE Access, vol. 5, pp. 12230-12256, 2017.

[14] S. Moayedi and A. Davoudi, "Distributed Tertiary Control of DC Microgrid Clusters," IEEE Transactions on Power Electronics, vol. 31, no. 2, pp.1717-1733, Feb. 2016.

[15] T. Dragicevic, X. Lu, J. C. Vasquez and J. M. Guerrero, "DC MicrogridsPart II: A Review of Power Architectures, Applications, and Standardization Issues," IEEE Transactions on Power Electronics, vol. 31, no. 5, pp. 3528-3549, May 2016.

[16] R. W. De Doncker, "Power electronic technologies for flexible DC distribution grids," 2014 International Power Electronics Conference (IPEC-Hiroshima 2014 - ECCE ASIA), pp. 736-743, 2014.

[17] M. Stieneker, J. Butz, S. Rabiee, H. Stagge and R. W. D. Doncker, "Medium-Voltage DC Research Grid Aachen," International ETG Congress 2015; Die Energiewende - Blueprints for the new energy age, pp. 1-7, 2015.

[18] M. Cupelli et al., "Port Controlled Hamiltonian Modeling and IDA-PBC Control of Dual Active Bridge Converters for DC Microgrids," IEEE Transactions on Industrial Electronics, vol. 66, no. 11, pp. 9065-9075, Nov. 2019.

[19] S. Zhao, Y. Chen, S. Cui, B. J. Mortimer and R. W. De Doncker, "Three-Port Bidirectional Operation Scheme of Modular Multilevel DC-DC Converters Interconnecting MVDC and LVDC Grids," IEEE Transactions on Power Electronics, vol. 36, no. 7, pp. 7342-7348, July 2021.

[20] K. Rouzbehi, J. I. Candela, A. Luna, G. B. Gharehpetian and P. Rodriguez, "Flexible Control of Power Flow in Multiterminal DC Grids Using DCऽCDC Converter," IEEE Journal of Emerging and Selected Topics in Power Electronics, vol. 4, no. 3, pp. 1135-1144, Sept. 2016.

[21] F. Li, Z. Lin, Z. Qian, J. Wu and W. Jiang, "A Dual-Window DC Bus Interacting Method for DC Microgrids Hierarchical Control Scheme," IEEE Transactions on Sustainable Energy, vol. 11, no. 2, pp. 652-661, April 2020.

[22] M. S. Agamy et.al, "An Efficient Partial Power Processing DC/DC Converter for Distributed PV Architectures," IEEE Transactions on Power Electronics, vol. 29, no. 2, pp. 674-686, Feb. 2014

[23] J. R. R. Zientarski,M. L. da Silva Martins,J. R. Pinheiro and H. L. Hey, "Evaluation of Power Processing in Series-Connected Partial-Power Converters," IEEE Journal of Emerging and Selected Topics in Power Electronics, vol. 7, no. 1, pp. 343-352, March 2019. 